\title{
Contribuições da Etnomatemática para formação dos Professores Indígenas do Estado do Tocantins
}

\author{
Contributions of Ethnomathematics to the Training of Indigenous Teachers of the State \\ of Tocantins
}

\author{
Hélio Simplicio Rodrigues Monteiro ${ }^{1}$
}

\begin{abstract}
Resumo
Este trabalho é um recorte revisado e traz parte das reflexões feitas na dissertação de mestrado realizada e defendida pelo autor no Instituto de Educação Matemática e Científica da Universidade Federal do Pará ${ }^{2}$. Procura refletir sobre as contribuições da etnomatemática na formação dos professores indígenas que cursam o Magistério Indígena do Estado do Tocantins. O curso é oferecido pela Secretaria de Educação do Estado do Tocantins e funciona nos meses de recesso escolar, para professores que já atuam nas escolas de suas respectivas aldeias, estes são escolhidos pela própria comunidade. O interesse surgiu a partir da observação, onde o autor foi professor formador, das dificuldades encontradas pelos professores índios que cursam o Magistério Indígena nesse estado. Essas dificuldades referem-se tanto na compreensão do conteúdo da matemática escolar, quanto na interseção desta com os aspectos da sua cultura presentes no cotidiano da aldeia. A cultura indígena é rica em conhecimentos que podem servir de motivadores de temas geradores para práticas educativas em sala de aula, tais como a confecção de objetos utilitários e rituais, pintura corporal, festas rituais e atividades como a caça, a pesca, e as atividades de roça e de coleta. Essa diversidade envolve saberes tradicionais, de forma integrada, onde o conhecimento matemático se faz presente. A pesquisa teve como objetivo geral investigar o quanto os estudos etnomatemáticos podem contribuir com as diferentes relações e práticas do meio cultural indígena, podendo as mesmas serem utilizadas como elementos motivadores no ambiente escolar para o fortalecimento da identidade cultural indígena e particularmente para o aprendizado da matemática. Teve como questão norteadora: por que, tendo os professores indígenas todo um arsenal que o circunda em todos os seus afazeres, com suas práticas sociais, que englobam aí práticas que nomeamos matemática, em total sintonia com sua cosmologia, por que esses professores não utilizam esses afazeres em suas aulas no geral e mais especificamente em suas aulas de matemática? Como podemos reconhecer as facilidades e os impedimentos, referentes ao professor indígena, em utilizar os elementos da própria cultura indígena em atividades nas aulas de Matemática? Os procedimentos metodológicos utilizados são de abordagem do tipo qualitativa e incluem vários instrumentos de análise utilizados como diário de campo, entrevistas e relatórios de viagens. Nesse propósito, a pesquisa tem como base a Etnomatemática e a Educação Intercultural Bilíngue nas pesquisas de D’Ambrosio (1990, 2002), Domite (2009), Cauty (2009), dentre outros. A relação entre esses saberes e a matemática escolar, na perspectiva etnomatemática, poderá agregar valores significativos na compreensão e apreensão de novos saberes sem perder de vista a sua riqueza cultural, ou seja, tendo como suporte a sua cultura, se apropriar de conhecimentos que sejam de suma importância na defesa de seus interesses, nas relações estabelecidas com a sociedade envolvente. Por fim o trabalho sinaliza que, do ponto de vista da concepção de educação escolar indígena e da educação intercultural bilingue, esse pode ser o fio
\end{abstract}

\footnotetext{
${ }^{1}$ Doutor pela Universidade Estadual de Campinas. Professor do curso de Licenciatura em Educação do Campo da Regional Goiás da Universidade Federal de Goiás. E-mail: heliosimplicio@gmail.com

2 Rodrigues-Monteiro, H. S. Magistério Indígena: contribuições da Etnomatemática para a formação dos professores indígenas do Estado do Tocantins. Dissertação (Mestrado em Educação em Ciências e Matemáticas) - Universidade Federal do Pará. Belém. 2011.
} 
condutor na valorização dos saberes tradicionais, sua vivência e fortalecimento de relações, sem perder de vista a apropriação de outros saberes, oriundos de outras práticas culturais.

Palavras-chave: Etnomatemática; Magistério Indígena; Professor Indígena.

\begin{abstract}
This work is a revised clipping and brings part of the reflections made in the master dissertation held and defended at the Institute of Mathematical and Scientific Education of the Federal University of Pará, defended by the author. It seeks to reflect on the contributions of ethnomathematics in the training of indigenous teachers who attend the Indigenous Magisterium of the State of Tocantins. The course is offered by the Secretary of Education of the State of Tocantins and works in the months of recess, for teachers who already work in the schools of their respective villages, these are chosen by the community itself. The interest arose from the observation, where the author was a teacher teacher, of the difficulties encountered by Indian teachers who attend the Indian Magisterium in this state. These difficulties refer both to the understanding of the content of school mathematics and to its intersection with the aspects of its culture present in the everyday life of the village. The indigenous culture is rich in knowledge that can serve as a motivator of generating themes for classroom practices such as making objects and ritual rituals, body painting, ritual festivals and activities such as hunting, fishing, and activities and harvesting. This diversity involves traditional knowledge, in an integrated way, where mathematical knowledge is present. The research had as general objective to investigate how the ethnomathematical studies can contribute to the different relations and practices of the indigenous cultural environment, being able to be used as motivating elements in the school environment for the strengthening of indigenous cultural identity and particularly for the learning of mathematics. It had as a guiding question: why, with indigenous teachers having an arsenal that surrounds them in all their tasks, with their social practices, which encompass practices that we call mathematics, in full harmony with their cosmology, why these teachers do not use these assignments in your classes in general and more specifically in your math classes? How can we recognize the facilities and impediments, referring to the indigenous teacher, in using the elements of indigenous culture itself in activities in Mathematics classes? The methodological procedures used are qualitative in approach and include various analytical tools used as field diary, interviews and travel reports. In this purpose, the research is based on Ethnomathematics and Bilingual Intercultural Education in the researches of D'Ambrosio (1990, 2002), Domite (2009), Cauty (2009), among others. The relation between these knowledge and school mathematics, from the ethnomathematical perspective, can add significant values in the understanding and apprehension of new knowledge without losing sight of its cultural richness, that is, from its culture, appropriating knowledge that is of importance in the defense of their interests, in the relations established with the surrounding society. Finally, the paper indicates that, from the point of view of the conception of indigenous school education and bilingual intercultural education, this can be the guiding principle in the valorization of traditional knowledge, its experience and strengthening of relations, without losing sight of the appropriation of others knowledge, from other cultural practices.
\end{abstract}

Keywords: Ethnomathematics; Indigenous Teaching; Indigenous Teacher.

\title{
Introdução
}

A oportunidade de trabalhar a disciplina de matemática sob a perspectiva da Etnomatemática no curso de Magistério Indígena do Estado do Tocantins, revelou-se como o momento propício para procurar entender, mais profundamente, que existem diferentes formas de se estar no mundo, diferentes formas de agir sobre e que essas diferentes formas se manifestam nas peculiaridades próprias de cada povo, de cada região, de cada grupo, ou seja, depende daquilo que chamamos de cultura.

Procurar entender essas diferentes manifestações com práticas sociais que nomeamos matemática, tão fortemente presentes nas atividades corriqueiras das comunidades indígenas, como caça e pesca, dentre outras, desses professores e, portanto, dentro de uma dinâmica social, com valor social e construídas holisticamente é que surgiu a necessidade de 
DOI: https://doi.org/ 10.20396/zet.v26il.8650884

desenvolver esse estudo. Sobretudo para problematizar nas aulas esses momentos em que afloram, como já disse, esses saberes distintos em proporcionar momentos que podem vir a se tornar de grande aprendizado.

A pesquisa teve como objetivo geral investigar o quanto os estudos etnomatemáticos podem contribuir com as diferentes relações e práticas do meio cultural indígena, podendo as mesmas serem utilizadas como elementos motivadores no ambiente escolar para $o$ fortalecimento da identidade cultural indígena e particularmente para o aprendizado da matemática.

Em suma, essa relação propicia um processo dialógico com professores e pesquisadores de matemática sobre meios e critérios para o ensino e aprendizagem da matemática em uma relação com o contexto cultural.

Entendendo dessa forma que, se desde a formação inicial, ele já for conduzido a ter um olhar diferenciado, então esse aluno-professor já começará a trabalhar na visão da valorização da sua cultura, trabalhando também o currículo de forma diferenciada, mostrando os conteúdos de forma integrada, agora sob o ponto de vista da sua cultura e estabelecendo com esta as relações com as outras disciplinas, para, a partir disso, oferecer ao alunoprofessor indígena, melhores condições de conduzir o seu fazer pedagógico refletindo esse seu fazer de forma mais ampla.

A pesquisa se deu no Estado do Tocantins com alunos-professores indígenas que participam do Curso De Formação Inicial em Magistério Indígena, oriundos dos sete povos indígenas que possuem terras indígenas nesse estado, que são: Apinayé, no município de Tocantinópolis; Karajá Xambioá, em Xambioá; Karajá, na ilha do Bananal; Javaé, na ilha do bananal; Krahô, em Itacajá; Krahô Kanela, Lagoa da Confusão e Xerente no município de Tocantínia.

Os procedimentos metodológicos utilizados são de abordagem do tipo qualitativa. Como técnica ou instrumento de pesquisa utilizado para a construção de dados, utilizei-me da observação participante, dada a interação, as relações estabelecidas com os sujeitos, onde não foram raras as vezes que obtive dados importantes ao desenvolvimento deste trabalho em conversas informais e formais que se davam tanto no Magistério Indígena quanto em visitas às aldeias. Além, obviamente, dos momentos planejados sistematicamente, possibilitados nas aulas do Curso. Os procedimentos metodológicos incluem ainda vários instrumentos de análise utilizados como diário de campo, entrevistas, relatórios de viagens, dentre outros.

\section{A Etnomatemática como possibilidade para a Formação de Professores Indígenas}

Há no momento uma crescente literatura abordando o ensino de matemática em comunidades indígenas. Muitos pesquisadores, entre eles Leme (2010), Costa (2007), Ferreira (2005), Domingues (2006), Rodrigues-Monteiro (2016) tem colocado no centro de suas atenções o programa denominado Etnomatemática como um dos possíveis caminhos na 
tentativa de diminuir as dificuldades no ensino desta disciplina, tanto nos cursos de formação de professores indígenas, como nas escolas presentes nas aldeias.

Esse crescente interesse se deve a vários fatores, dentre os quais, a procura por mudança de paradigma, que atualmente busca um ensino de matemática tomando como elemento motivador, o repertório cultural do aluno. Colocando em xeque o ensino altamente formalista da matemática escolar, que privilegia o emprego de técnicas e demonstrações em total dissonância com a realidade cultural do aluno e da escola e ainda nos moldes da educação bancária. Muito embora essa seja uma característica peculiar à essa ciência.

Neste sentido, fazer um estudo em etnomatemática significa aceitar como válidos os saberes e fazeres característicos de um grupo, de sua forma de vida, e que esses saberes e fazeres são vitais nas suas relações, pois,

O cotidiano está impregnado dos saberes e fazeres próprios da cultura. A todo instante, os indivíduos estão comparando, classificando, quantificando, medindo, explicando, generalizando, inferindo e, de algum modo, avaliando, usando, os instrumentos materiais e intelectuais que são próprios à sua cultura (D'AMBROSIO, 2002, p.22).

É preciso aqui explicar que o uso da palavra grupo refere-se a um coletivo com características próprias, e que não necessariamente seja apenas um grupo étnico, como os indígenas, os negros, os ciganos, os brasileiros, os japoneses, etc., pois o conceito de etnomatemática ultrapassa as barreiras da etnicidade. Assim, a palavra grupo além de se referir a um grupo étnico, também pode designar um grupo de advogados, médicos, pedreiros, professores e assim por diante, pois são grupos com suas especificidades culturais. D’Ambrosio (1990) explica o uso do termo esclarecendo que:

[...] etno se refere a grupos culturais identificáveis, como por exemplo, sociedades nacionais tribais, grupos sindicais e profissionais, crianças de uma certa faixa etária etc, e inclui memória cultural, códigos, símbolos, mitos e até maneiras específicas de raciocinar e inferir. Do mesmo modo a Matemática também é encarada de forma mais ampla que inclui contar, medir, fazer contas, classificar, ordenar, inferir e modelar. (D’AMBRÓSIO, 1990, p. 17-18).

Dessa forma, assim como a etnomatemática se constitui por uma visão de homem e de mundo, também é possível o seu uso como uma ferramenta que poderá proporcionar aos professores de um modo geral e aos indígenas em particular, muito mais do que visualizar em suas práticas culturais elementos que possam identificar como práticas matemáticas. Ela também contribui para a reflexão sobre essas práticas e o seu valor social na sua comunidade, e, também, sobre quais elementos da matemática serão necessárias apreender para que consigam estabelecer relações com o mundo.

Sebastiani Ferreira (1994) em um artigo publicado pela revista Em Aberto fala em matemática materna como sendo aquele conhecimento matemático que faz parte do repertório cultural da criança, e que traz este conhecimento para a escola. Neste artigo, Sebastiani Ferreira fala da importância de se levar para a aula de matemática, inclusive do não-índio, outras formas de expressão matemática que não a eurocêntrica ocidental com 
verdades universais e absolutas. Deve-se buscar a superação desse estado com a proposição de um trabalho pedagógico que mostre aos alunos diferentes lógicas e práticas matemáticas, e que o Brasil pode servir de exemplo nesse trabalho pedagógico dado a grande diversidade cultural de nosso país. Sebastiani Ferreira ainda sustenta que "alguns livros didáticos dão numerações egípcias, babilônias, romana e mesmo maia, mas nenhum cita a numeração de alguma tribo brasileira" (Sebastiani Ferreira, 1994, p. 94).

Dessa forma, para os indígenas, um fator preponderante para as suas relações com a sociedade envolvente é serem capazes de "[...] perceber como os grupos se apropriam dos saberes, ou seja, como compreendem e usam as informações que recebem, é tão importante quanto resgatar o que é próprio da sua cultura.” (Monteiro \& Pompeu Junior, 2001, p.51).

Isso fica ainda mais evidente nas palavras de um aluno do Magistério Indígena, por ocasião de um dos encontros do curso do Magistério Indígena, da etnia Karajá. Ao ser perguntado sobre quais conhecimentos matemáticos achava necessário aprender, ele respondeu que a matemática financeira, por se tratar de um conhecimento necessário muito utilizado nas situações de negócios entre os indígenas e o comércio das cidades onde vendem seus produtos ou fazem suas compras.

Esse depoimento mostra a preocupação que devemos ter como profissionais com os conteúdos envolvidos nas aulas de matemática e principalmente na elaboração do currículo para as escolas indígenas.

Dessa forma se faz necessário uma participação significativa das comunidades indígenas no momento da elaboração do currículo dos cursos onde há demanda indígena e não apenas naqueles específicos, o currículo precisa necessariamente ser flexível e atender aos anseios das comunidades e nesse sentido, não apenas das comunidades indígenas, mas da sociedade como um todo.

Na abordagem dessa questão, Pedro Paulo Scandiuzzi, ao pesquisar o povo Kuikúro, localizado no Parque Indígena do Xingú, no Estado do Mato Grosso é enfático ao dizer que:

Com o programa etnomatemática reconhecemos, assim, a capacidade social de decisão e direito de participação na programação dos processos de formação dos povos indígenas. Reconhecemos e aceitamos a transculturalidade e o direito de manejar, de maneira autônoma, os recursos de sua cultura. Reconhecemos que são eles, os povos indígenas que devem decidir seu futuro, segundo um projeto que parta de seus interesses e aspirações (SCANDIUZZI, 2009, p. 25).

O autor é taxativo ao afirmar que a introdução da instituição escola nas comunidades indígenas, aos moldes da chamada cultura ocidental, acaba por diluir a sua cultura, uma vez que, não dá o tempo necessário às transformações do mito. Aponta que o programa etnomatemática pode diminuir esses impactos negativos, visto que ela se propõe ao diálogo, ao respeito, ao reconhecimento da diversidade.

A esse respeito ainda, Rogério Ferreira (2005) na sua tese de doutoramento, traz a tona que, apesar dos impactos da introdução da educação escolar em comunidades indígenas, 
[...] vê-se a educação escolar - uma entre tantas outras formas de educar - como elemento de suma importância nos contextos que a tem como uma componente formativa de cultura e sociedade. Nas realidades indígenas, porém, ela surge como algo estranho. Nos últimos séculos, o percurso histórico das sociedades indígenas em nível de Brasil mostra que a educação escolar destinada aos povos indígenas não se reduziu à estranheza, mas a uma clara interferência com óbvios prejuízos de ordem sócio-cultural. Assim, com a nova dinâmica estabelecida, o que levou as sociedades indígenas a hoje possuírem um novo perfil, a educação escolar surge como fonte estruturante em seus meios e, portanto, surge como instrumento necessário ao processo de inserção política junto à sociedade que, na atualidade, comanda as ações e tomadas de decisão. (FERREIRA, 2005, p. 193).

$\mathrm{O}$ autor em referência a essa realidade nos coloca que:

[...] a etnomatemática responde com a construção de uma escola diferenciada que ganhe significado junto ao grupo étnico ao qual servirá. Para que a distinção se efetive, surge também como necessidade refletir criticamente, em amplidão, sobre a história da educação escolar. A compreensão dos paradigmas que a sustentam no passado e os paradigmas que hoje para ela estabelecem novos rumos, poderá melhor respaldar as tomadas de decisão por parte dos indígenas no que tange à educação escolar que almejam para os seus povos; quando almejam. As formações voltadas aos professores indígenas podem erguer espaços favoráveis ao debate em torno desta última necessidade. (Idem, p. 193).

É nesse sentido que se encontra a dimensão político-emancipatória da etnomatemática, evidenciando a necessidade de escolha por parte dos povos indígenas do modelo de educação escolar a ser implantado e implementado em suas comunidades. Muito embora isso seja um processo lento, dado o grau da tutela a que a maioria das comunidades indígenas se encontram.

$\mathrm{Na}$ busca por entender mais detalhadamente as dificuldades dos alunos-professores indígenas em fazer abordagens nas atividades didáticas da sua própria etnia, no desenvolvimento de uma atividade pedagógica durante a realização do Magistério Indígena, foi pedido que lessem e refletissem sobre alguns depoimentos de professores indígenas contidos no Referencial Curricular Nacional para as Escolas Indígenas (RCNEI). Os depoimentos são esses:

A matemática não é uma matéria nova, mas ela já é muito velha, já vem há muito tempo sendo usada pelos homens que existem e já existiram também. O que acontece é que ninguém conhecia o que era. Mas depois, quando foi descoberta, ai que foi colocado o nome de matemática. Até agora todo mundo conhece com esse nome. Antigamente, por mais analfabeta que fosse, a pessoa já usava matemática sem saber. Porque já fazia tudo calculado: a distância, o tamanho etc. E assim já estava funcionando a matemática. (BRASIL, 2002, p.159).

E esse:

A matemática existe principalmente nos objetos como o artesanato. Os desenhos da peneira são igual matemática... não é qualquer um que faz, tem que ser profissional, tem contar os talinhos... Eu aprendi assim, sem saber se era matemática ou não. Agora, depois que a gente aprendeu que aquilo lá era uma matemática, aí eu sabia que eu já tinha aprendido matemática indígena. (Idem, p. 161). 
O objetivo de mostrar os depoimentos foi o de fazer os alunos-professores indígenas refletirem a respeito de como a matemática pode estar presente tanto no dia-a-dia da aldeia, quanto na cidade, na escola, no comércio, entre outras atividades. Essa reflexão serviria de base para as respostas às perguntas que faria logo após isso, mesmo sabendo que os depoimentos influenciariam nas suas respostas.

A primeira pergunta feita aos alunos-professores foi a seguinte: "Em quais atividades no dia a dia da aldeia envolvem ou está presente a matemática?”. Um professor Karajá respondeu o seguinte, que:

A matemática apresenta em todas as atividades, quando a gente vai fazer algum plantio tem que saber quantos litros vai plantar. Quando você vai pescar tem que saber quantos peixes você pegou. Quando fazemos uma festa tradicional temos que saber quantos cantores tem porque temos que formar dois grupos de dançadores. Quando vamos para sala de aula temos que ter o diário pra saber quantos alunos temos em sala de aula, se vamos correr, envolve a matemática porque temos que colocar em grupo. (Professor da etnia Karajá-Xambioá).

Outro professor, Xerente, deu a seguinte resposta:

$\mathrm{Na}$ festa cultural indígena envolve matemática, quantas pessoas estão na corrida de tora existe matemática, tem dois times por igual, por exemplo: se é 20 de um lado, tem que ser 20 do outro lado. Os artesanatos de talo de buriti para enfeitar borduna, arco, peneira, tem que colocar os talinhos de enfeitar para dar tudo certo, os coloridos, por exemplo: os vermelhos, preto e branco tem seu lugar apropriado se for de ímpar vai de ímpar, se for de par vai só de par e assim continua. Dentro da casa tem matemática, quantas pessoas tem nessa casa no total, quantas pessoas tem na aldeia, quantos alunos nas escolas, quantas tarefas ou alqueires de roça a aldeia tem, quantos rios tem na área, quantos gados tem na aldeia. (Professor da etnia Xerente).

As respostas dos dois alunos-professores evidenciam o conhecimento que eles têm da presença de elementos da matemática no cotidiano da aldeia. É nesse sentido que entendemos que muitos materiais de estudo podem ser desenvolvidos na perspectiva da etnomatemática, como também nas articulações com as outras disciplinas.

Valorizar esses conhecimentos, propondo atividades que tenham como eixo norteador o saber da tradição, significa fortalecer uma identidade cultural e, a partir daí transcender, ir além não só do conhecimento tradicional como também buscar as interlocuções com as demais disciplinas do currículo, de forma transdisciplinar.

Todavia, é importante observar que essa é uma questão difícil de por em prática e de muitos entraves, sobretudo as relacionadas ao ensino de matemática face a uma formação que não prepara para essa diversidade também os formadores de professores indígenas, pois, assim como a diversidade cultural é vista erroneamente como um problema posto, se tem também a diversidade linguística que acaba por dificultar o ensino dessa disciplina, entre outros fatores, pois, como enfatiza Domite (2009), 
Assim como as línguas, a matemática tem um importante papel a desempenhar neste movimento culturalmente situado. Historicamente, a participação e o alcance da matemática na vida das crianças e adultos indígenas têm sido causa de grande preocupação, e também tem sido tema de muitos programas de intervenção. E o estabelecimento de programas relacionados à matemática nas escolas indígenas é, em geral, mais difícil do que em outras disciplinas, pelo menos por duas razões. Primeiramente, como disciplina, a matemática é hoje também reconhecida como não isenta da influência cultural - ponto de vista muito bem discutido, hoje, pelos estudos etnomatemáticos. Segundo, há uma necessidade de aprendê-la, sobretudo para o avanço da economia, porém há uma limitação de ordem prática: os professores de matemática, mesmo os mais qualificados, têm pouca possibilidade de atuação ante o despreparo para uma atuação/educação intercultural e a exigência da língua. (DOMITE, 2009, p.183).

André Cauty (2009) nos dá algumas pistas nesse sentido e nos chama a atenção sobre os motivos pelos quais o ensino de matemática nas escolas indígenas ainda se dá exclusivamente em línguas europeias, língua portuguesa no caso do Brasil. Esse mesmo autor nos aponta três razões para isso,

A primeira está ligada ao fraco desenvolvimento das línguas especializadas e dos subsistemas, como por exemplo, o da numeração. Para ensinar o cálculo na língua materna das crianças da escola bilíngüe, seria preciso começar pela criação das neonumerações nas quase duzentas línguas indígenas do Brasil cujas numerações faladas nomeiam apenas os primeiros numerais e se revelam penosas e inadequadas na execução de cálculos mesmo simples e com números inteiros inferiores a cem. A segunda está ligada à imensa diversidade das línguas indígenas; isso faz com que o emprego do português nas escolas bilíngües seja uma solução de urgência adotada pelos professores em sala de aula. A terceira está ligada ao fato de que os adultos compreendem e aceitam que seus filhos recebam um ensino da língua dominante (que muitas vezes eles mesmos não falam), mas não vêem a utilidade no ensino escolar da língua indígena que é usada cotidianamente entre eles. (CAUTY, 2009, p. 42).

Mesmo não concordando em parte com o autor, como sua sugestão de se criar neonumerações nas línguas indígenas ${ }^{3}$, percebe-se que é então com base nesses entraves colocados por Cauty e por Domite que urge a necessidade para as comunidades indígenas, de se formarem professores de matemática oriundos de suas próprias comunidades. Somente eles - conhecedores que são de suas culturas - serão capazes de estabelecer pontes de diálogo entre as práticas matemáticas de sua cultura e a matemática escolar. Evita-se assim, a dicotomia entre ambas, com a matemática desenvolvida a partir de suas práticas sociais sendo ensinada de forma folclórica, enquanto a matemática escolar adquire legitimidade de saber válido.

Tentar vencer essas barreiras é tarefa sem dúvida complicada, menos árdua, no entanto a depender da postura do professor formador de professores indígenas, sendo o professor formador não indígena. E uma das possíveis vias no intento de vencer tais barreiras, seria pela etnomatemática, como bem coloca Scandiuzzi, quando diz que,

\footnotetext{
${ }^{3}$ Para uma discussão aprofundada sobre tradução do conhecimento matemático em Português para as línguas indígenas ver Rodrigues-Monteiro (2016).
} 
[...] para o etnomatemático, a educação indígena pode se realizar com a presença do educador não-índio, não para transferir nenhum tipo ou modelo de conteúdo, mas para que, no diálogo com os povos indígenas, eles possam reconhecer como científicas as construções produzidas por seus antepassados e - mediante essas produções científicas - compreender como se denominam em nossa cultura. O etnomatemático deve reconhecer a produção científica e educacional dos povos indígenas (produção está milenar) como uma entre tantas outras produzidas por diversos grupos sociais diferenciados. (SCANDIUZZI, 2009, p. 23).

Isso se faz necessário sobretudo porque o aluno-professor indígena sabe da importância de ensinar matemática na escola indígena, como podemos perceber nos depoimentos que respondiam a seguinte pergunta "É importante estudar/ensinar matemática na escola indígena? Por que?” Um professor da etnia Xerente respondeu que:

É importante porque estudar matemática é conhecer o mundo dos números, para facilitar a comprar, a vender, receber troco e dominar bem as atividades envolvidas e levar o conhecimento na sala de aula. E isso nos leva a ensinar aos nossos alunos de como vender, comprar, receber o troco e como gastar. E ensinar também o artesanato, de como fazer, de como pintar o corpo, contar pessoas, conhecer a sua idade. E através do estudo e conhecimento, preparar o aluno a aprender a matemática para o mercado de trabalho, e para lidar no comércio dentro de seus costumes, nas vendas de vários tipos de artesanatos.

Outro professor da etnia Xerente, assim a respondeu:

É importante estudar sim, porque quando nós falamos não percebemos números de matemática, mas quando saímos para pescaria contamos quantidades que pegamos, quantos peixes grandes, quantos peixes pequenos, que tipo de peixe foi mais pego durante a pescaria. Na caçada também vimos números porque podemos encontrar muitas madeiras, frutas, animais, passarinhos. Para nós índios os números começa da aldeia, alguns sabem outros não sabem. Temos quantidades de índios na aldeia, quantidades de crianças masculino e crianças feminina, quantidades de jovens masculino e jovens feminina, quantidades de homens e mulheres, quantidades de anciães e anciões e até quantidades de animais como cachorro, cadela, galo, galinha. Outros números que se pratica muito é sobre a contagem de artesanatos feitos pelos índios da aldeia, isso também contamos(...) por isso é importante ensinar matemática.

Um professor da etnia Krahô, ainda salientou que:

Pra nós indígenas é importante porque através de matemática, faz todos tipos de artesanato. Com matemática ajuda vários tipos de trabalho, por isso todos nós queremos aprender. Antigamente os mais velhos na sabiam ler, escrever, mas consegue fazer artesanato com matemática. Hoje nós educadores como professores índios já estudou com matemática [...] matemática é muito interessante pra aluno e não-aluno também.

É possível perceber por esses depoimentos que os alunos-professores reconhecem a importância de se ensinar matemática na escola indígena pelos seguintes motivos: 
DOI: https://doi.org/ 10.20396/zet.v26il.8650884

$1^{\circ}$ Tem a percepção de que em suas práticas sociais existem elementos que podemos identificar como sendo práticas matemáticas, e essas práticas pertencentes a cultura indígena são importantes ensinar na escola indígena, valorizando ainda mais a sua cultura;

$2^{\circ}$ Importante apreender a matemática do não-índio visto em seu sentido utilitário, como uma necessidade nas relações de comércio que estabelecem com a sociedade envolvente.

Com base nas respostas dessas duas perguntas feitas aos alunos-professores indígenas, surge a seguinte questão. Se os professores sabem, tem a noção de que em suas atividades cotidianas podemos identificar atividades envolvendo práticas matemática e, mais ainda, sabem da importância de se ensinar matemática na escola indígena pelos motivos expostos acima, por que eles não fazem uso desses elementos como recursos, procurando articular o saber cultural e a matemática escolar?

$\mathrm{Na}$ busca de encontrar uma resposta para compreender esse paradoxo, fez-se a seguinte pergunta: Há dificuldade em ensinar matemática na escola indígena? Se há, que dificuldades são essas?

Dentre as respostas obtidas, um professor Apinajé disse que:

Se o professor (indígena) não tiver capacitado de ensinar a matemática, o aluno não aprende, somar e nem multiplicar. O professor branco tem ensino diferente para ensinar aula teórica para os indígena. Na aldeia temos já o ensino médio e professores não índio que não tem dificuldade. Queremos ter um índio formado na aldeia.

No depoimento desse professor, é possível entendermos a preocupação do mesmo em ter professores indígenas saídos da própria etnia para trabalhar na escola da aldeia a disciplina de matemática, pois o professor não-índio "tem ensino diferente" para ensinar na aldeia, o que penso estar implícito nesta fala é a consciência de que o professor "branco" não irá fazer as articulações com as práticas sócio-culturais da etnia, privilegiando a matemática do não índio.

E com relação aos professores não-índios, sobretudo os formadores de professores indígenas, Helena Scavazza Leme apresenta três aspectos a respeito da formação superior de professores indígenas no estado do Mato Grosso do Sul. Esses aspectos são as motivações que levam estudantes indígenas a escolherem o curso de graduação em matemática, as suas dificuldades na $1^{\text {a }}$ série do curso e os motivos que os levam a desistir dele, nos diz ser importante

[...] a necessidade de haver por parte dos formadores um maior comprometimento com questões da própria cultura dos indígenas que está formando, para que os conteúdos que abordassem em sala de aula pudessem também ser apresentados com base na cultura daqueles que estão aprendendo. O formador acaba perdendo a oportunidade de envolver esses alunos que muito teriam a contribuir com os demais 
se soubesse e se interessasse em saber um pouco do saber do outro e incorporasse essas informações no dia a dia de sua disciplina. (LEME, 2010, p. 103).

Fica evidente nas colocações de Helena que o formador precisa se envolver mais com a cultura de seus formandos, se impregnar desses conhecimentos de forma a tornar mais significativos o aprendizado da matemática e dessa forma contribuir com a valorização da cultura indígena, sem evidentemente deixar de lado a contribuição das diversas civilizações ao longo da história humana.

Continuando nas reflexões dos depoimentos dos alunos-professores indígenas, uma professora e dois professores Xerente responderam, respectivamente, que:

Há dificuldade de nós ensinar a matemática não é tanto da nossa cultura, mas ensinar com língua portuguesa é muita dificuldade.

Realmente passa algumas dificuldades de ensinar matemática, porque alguns livros didáticos não é qualidade e os conteúdos é complicado para explicar melhor, e passa também a dificuldade na aldeia sobre a matemática porque não tem ainda alguns livros indígenas produzidos na língua indígena em Xerente sobre os números e também com as quatro operações que existe para que seja ensinado com a própria língua para que os alunos entendam melhor.

[...] Temos dificuldade é na matemática dos não índios é bem difícil, porque não temos materiais pedagógicos e as vezes não temos acompanhamento pedagógico na escola, e as informações que aprendemos é para dar aula mais básico e precisamos aprender mais.

Nos depoimentos desses alunos-professores vemos uma clara preocupação com o material pedagógico utilizado nas aulas de matemática, pois os mesmos além de serem escritos em língua portuguesa, privilegiam unicamente a cultura não indígena. É possível ainda perceber que os professores anseiam por material didático pedagógico produzido na língua indígena, mesmo o depoimento da professora não estar especificando o material pedagógico, fica evidente sua preocupação ao ensinar matemática na língua portuguesa, e isso obviamente se faz utilizando o livro didático, sendo este, geralmente, o único recurso disponível na escola indígena.

O depoimento de um professor Xerente enfatiza que:

Há dificuldade de ensinar a matemática não por parte de mim, por nós professores, aprendemos para ensinar, mas por parte dos alunos, e eu como professor tem vezes que fico sem saída. O porquê tantos números, porque que existe fração ordinário, múltiplo, divisão, multiplicação, subtração, quilômetro, centímetro, milímetro. Então é muita coisa de matemática, nós como professor indígenas tem vezes que aluno pergunta o porquê tudo isso, daí eu respondo como professor, afirmando que a matemática é dos brancos. A matemática muita coisa não é traduzido na nossa língua, por exemplo do km, cm, ml, mil, milhões e trilhões, decâmetro, hectômetro, litro, decímetro, etc. 
Esse depoimento também evidencia a preocupação em ensinar matemática na aldeia em língua portuguesa, pois além de praticamente inexistir material na língua indígena, muitos termos não fazem sentido na cultura da etnia.

Todavia, esses depoimentos entraram em contradição com algumas respostas a seguinte pergunta feita aos alunos-professores "Que materiais você usa para ministrar suas aulas de matemática?”. Obtive as seguintes respostas,

Folha, lápis, papel, etc... (Professor da etnia Xerente).

Material didático, material dourado. (Professor da etnia Javaé).

Na pintura e nos trabalhos de roça, mostrando como era no passado. (Professor da etnia Karajá Xambioá).

Livros, cadernos, recorte de figuras, jogos da memória, cartolina, pincéis, chamex, etc... (Professora da etnia Krahô Kanela).

Eu começa trabalhar matemática com material de artesanato, como fazer pulseira, ou colar, esteira... (Professor da etnia Krahô).

Livro didático, e outros recursos também que servem para fazer conta com os números. (Professor da etnia Karajá).

De acordo com as respostas 3 e 5, somos induzidos a pensar que esses professores fazem uso dos aspectos culturais nas suas aulas de matemática, porém, esses mesmos professores fizeram colocações em depoimentos anteriores que entram em contradição com essas respostas acima. Analisando o diário de campo, das supervisões pedagógicas que realizei nas aldeias, verifiquei entre as anotações que os professores utilizavam, basicamente nas aulas de matemática, o livro didático nas suas aulas.

Essa constatação vem do fato de que não foram raras as vezes em que, ao chegar na aldeia, o professor indígena sabendo que eu sou professor de matemática, me pedia explicações de algum conteúdo de matemática contido no livro didático. Ao indagar sobre o que mais utilizavam além do livro didático eles respondiam que apenas o livro.

Também obtive como resposta de que eram cobrados pelos supervisores indígenas para cumprirem com o conteúdo programático do livro didático da série a qual estavam trabalhando.

A escola diferenciada e específica, com calendário próprio, que respeite as festas tradicionais, rituais, colheitas que mobilizam toda a comunidade, na prática não vem acontecendo a contento. Isso leva a crer de um modo geral, que muitas ainda estão restritas a concepção tradicional de educação, usando a cultura apenas como um recurso e não como a essência de todo o processo de aprendizagem.

Enfim, são muitos os entraves que dificultam um ensino de matemática com qualidade, que respeite os conhecimentos tradicionais dos grupos em questão como pudemos perceber no decorrer deste trabalho. Uma alteração nesse cenário exige mudanças significativas na concepção de educação, como um todo, uma mudança de paradigmas, de pensamento. 
Todavia, para que essas mudanças se efetivem, se faz necessário primeiro que todos nós, profissionais de diversas áreas reconheçamos que o modelo de educação ainda vigente encontra-se em esgotamento, devido às novas configurações dos alunos que chegam ao ambiente escolar.

Portanto, esse modelo não atende às nossas necessidades, gerando um sentimento de insatisfação entre alunos e professores. Diante desse quadro, urge a busca de novas concepções e novos instrumentos de ensino que possibilitem a realização de uma aprendizagem efetiva.

\section{Considerações Finais}

A minha experiência de professor do Curso de Formação Inicial, no Magistério Indígena do Estado do Tocantins, somadas as de supervisões pedagógicas realizadas nas escolas indígenas, foram sem dúvida fundamentais para a elaboração deste trabalho de pesquisa. Foi a partir delas que surgiram as inquietações e insatisfações que desembocaram no objeto e nas problemáticas de pesquisa que foram propostas.

O espaço de formação do Magistério Indígena, problematizado neste trabalho, é um valioso laboratório de convivência, diálogos, trocas de experiências entre culturas, além da oportunidade de crescimento profissional. Os conhecimentos gerados nas interseções de visões de mundo, ricas e diferenciadas, certamente podem e devem contribuir efetivamente para o redimensionamento da concepção de educação indígena e da formação de professores "índios" e "não-índios".

Em relação à Educação Escolar Indígena os indicadores que apontam para esse quadro são: a falta de interesse dos alunos; o alto índice de evasão; as atividades escolares desvinculadas das ações da comunidade; professores perdidos sem saberem exatamente o que fazer em aula, etc.

A proposição de diálogos permanentes, ouvindo as comunidades em seus anseios, poderá tornar possível o desenvolvimento de projetos que satisfaçam as suas reais necessidades. Nesse contexto, os professores formadores também poderão balizar suas ações pedagógicas, de tal forma a tornar o ensino e a aprendizagem de matemática significativa para os alunos-professores em formação.

Ao refletir sobre as atividades realizadas no curso de formação, em relação à educação escolar indígena e a educação indígena, reafirmo a necessidade de se criar políticas de fomento à produção de material didático específico para os povos indígenas, além de materiais referenciais para a formação de professores indígenas, ainda incipientes.

Urge que os saberes tradicionais dessas comunidades estejam presentes na educação escolar, para além de simples atividades ou tópicos abordados em disciplinas como arte ou cultura indígena. Eles poderão ser abordados em todas as disciplinas do currículo e, evidentemente, na disciplina de matemática, foco deste trabalho. 
Em relação à educação escolar indígena, o conhecimento tradicional, oriundo de suas práticas sociais, deve ser apresentado de forma sistematizada, buscando-se os elementos que identificam a cultura e guardem relação com o conteúdo escolar.

Em relação ao ensino da matemática, poderão ser identificados os elementos da cultura que envolvam práticas matemáticas, como a quantificação, a medição, a espacialidade, a inferência, dentre outros. A partir daí, deve-se estabelecer as mediações dialógicas com a matemática escolar, valorizando, fortalecendo e ampliando as suas práticas culturais, além de promover o acesso a outras formas de conhecimento e culturas.

Nessa perspectiva proponho como um dos possíveis caminhos para a construção dessas mediações, as práticas educativas e pedagógicas fundamentadas na concepção etnomatemática. Assim o faço por entende-la embasada na alteridade, ou seja, no respeito ao outro que é diferente de mim; nas trocas inter e intra culturais, já tão mencionadas ao longo deste trabalho; além da necessidade de convivência e de diálogo na interlocução entre as culturas, na apreensão e produção do conhecimento.

Formadores e professores fundamentados na atitude etnomatemática, como bem enfatiza o professor D’Ambrosio (2002), sem dúvida poderão ressignificar o ensino dessa disciplina, esse "corpo estranho" que ainda atemoriza muitos educandos.

A educação escolar indígena precisa estar fundamentada e a serviço das particularidades referentes a cada cultura, enquanto fator de reconhecimento, valorização e fortalecimento. Isso em contraposição a dicotomia ainda existente entre a diversidade e a homogeneização das culturas, de caráter generalista, e com o propósito de disseminação de valores que não fazem parte de suas culturas e o que é pior, servindo de elemento dissipador dessas culturas.

Este estudo enfatizou alguns aspectos expostos anteriormente, como indícios dos entraves que dificultam o ensino de matemática e de outras áreas de conhecimento, por parte dos alunos-professores indígenas nas escolas de suas aldeias. Contudo, que eles se constituam em desafios para que empreendamos os nossos melhores esforços, com determinação e perseverança, na busca de alternativas para as suas superações cotidianas.

\section{Referências}

Brasil (2002). Referencial Curricular Nacional para as Escolas Indígenas. Brasília, DF: MEC. Cauty, A. (2009). Como nascem e se desenvolvem as tradições escritas matemáticas. Exemplos Mesoamericanos (pp.29-52). In M. C. C. B. Fantinato (Org.), Etnomatemática: novos desafios teóricos e pedagógicos. Niterói: Editora da UFF.

D’Ambrósio, U. (2002). Etnomatemática: elo entre as tradições e a modernidade. Belo Horizonte: Autêntica.

D’Ambrósio, U. (1990). Etnomatemática: arte e técnica de aprender. São Paulo: Ática. 
DOI: https://doi.org/ 10.20396/zet.v26il.8650884

Domite, M. C. S. (2009). Perspectivas e Desafios da Formação do Professor Indígena: O formador externo à cultura no centro das atenções. In M. C. C. B. Fantinato (Org.), Etnomatemática: novos desafios teóricos e pedagógicos. Niterói: Editora da UFF.

Ferreira, R. (2005). Educação Escolar Indígena e Etnomatemática: a pluralidade de um encontro na tragédia pós-moderna. Tese de Doutorado em Educação. São Paulo: Universidade de São Paulo.

Leme, H. A. S. (2010) Formação Superior de Professores Indígenas de Matemática em Mato Grosso do Sul: Acesso, Permanência e Desistência. Dissertação de Mestrado em Educação. São Paulo: Universidade de São Paulo.

Monteiro, A., \& Pompeu Junior, G. (2001). A matemática e os temas transversais. São Paulo: Moderna.

Rodrigues-Monteiro, H. S. (2011). Magistério Indígena: contribuições da Etnomatemática para a formação dos professores indígenas do Estado do Tocantins. Dissertação de Mestrado em Educação em Ciências e Matemáticas. Belém: Universidade Federal do Pará.

Rodrigues-Monteiro, H. S. R. (2016). O Ensino de Matemática na Educação Escolar Indígena: (Im) possibilidades de tradução. Doutorado em Ensino de Ciências e Matemática. Campinas: Universidade Estadual de Campinas.

Scandiuzzi, P. P. (2009). Educação Indígena x Educação Escolar Indígena: uma relação etnocida em uma pesquisa etnomatemática. São Paulo: Editora UNESP.

Sebastiani Ferreira, E. (1994). A importância do conhecimento etnomatemático indígena na escola dos não-índios. Em Aberto, 14 (62), 89-95.

Recebido em: 31/10/2017

Aprovado para publicação em: 11/03/2018 